\title{
Casual Carpooling-Enhanced
}

Kalon L. Kelley, Consultant

\begin{abstract}
Casual carpooling currently functions in environments where, because there is an HOV lane, riders and passengers join together to gain access to that lane. In this article, technology is introduced that will allow casual carpooling to function in areas without HOV lanes by providing an administrative system that records actual carpooling behavior so that incentives other than access to an HOV lane can be made available. This technology also addresses some of the current shortcomings associated with casual carpooling such as personal safety, the "free rider" problem, and the disincentive to maximize the number of passengers sharing a ride. The article concludes with comments on funding enhanced carpool programs including a hypothetical comparison of a program providing monetary incentives for carpooling to the alternative construction of new HOV lanes.
\end{abstract}

\section{Introduction}

Casual carpooling refers to the sharing of a ride with a driver and one or more passengers, where the ridesharing between the individuals is not established in advance but coordinated on the spot. While there may be a variety of motives for ridesharing, the expression refers primarily to commuting situations where the driver is incentivized to pick up passengers so as to allow for transit using a high occupancy vehicle (HOV) lane. This type of carpooling has been around for quite a number of years and is characterized by its informality and lack of governance. Meeting sites tend to evolve where there is reasonable parking (for passengers who may drive to the site and leave their cars) and proximity to major transportation corridors that provide HOV lanes. Casual carpooling has become a recognized 
cultural phenomena in places as diverse as Washington D.C., Pittsburgh, Houston, and San Francisco.

Casual carpooling is often considered a win-win activity. Drivers get access to transit lanes that reduce the length of their commute; passengers get a free commute to work. The community benefits by a reduction in vehicles on the road with its panoply of benefits. ${ }^{1}$

\section{Technology for Carpools}

Radio frequency identification devices (RFID) are now used in a variety of environments involving vehicles. An overview of toll collection systems is described by Saranow (2005), and the U.S. Border Patrol is now using automatic vehicle identification (AVI) technology to speed border crossings (U.S. Customs 2006). While these transponders identify a vehicle, that is all they do.

RFID devices are also used to identify people. For example, a major oil company makes available small keychain devices that can be waved by a gas pump to pay for a gasoline purchase; this technology is being extended to other retailers.

The proposal herein is to use a transponder that, physically comparable to the dashboard-positioned toll collection transponders, has the additional capability of reading and storing in memory individual RFID devices when they are passed in proximity to the transponder. Then, when interrogated, the transponder transmits its ID along with the individual IDs that were read and stored.

There is a one-time registration process where a potential driver registers with the administrator and receives an enhanced transponder. ${ }^{2}$ An individual participating in the program as a passenger will register and receive an individual RFID device.

The casual carpool begins when a driver enters his vehicle and turns on the transponder. At a collection point, any rider entering the vehicle passes his RFID device by the transponder, which beeps to indicate that the device was read and then records in memory the rider's ID. As the vehicle has occasion to travel by a reading station, the transponder will transmit its own ID along with IDs identifying the occupants. The reading station will periodically transfer its collected information to the central processing system. This allows for a historical record of carpooling events (who, where, and when) to be created effortlessly. This is the kind of information now manually collected by various carpooling systems to allow for reward- 
ing participants, with the implication that a framework for incentivizing people to form traditional carpools can apply as well to casual carpooling.

Identifying the transit corridors to be monitored is critical as it will not in general be possible to have transponder readers on all highways and surface streets that might be used for commuting. With multiple corridors and destinations, the placement of readers would need to be done with care, in particular to avoid situations where commuters are motivated to use a less efficient route simply to ensure that they pass through a transponder reader and get credit for their commute. Establishing a casual carpooling collection point would be subject to the same rationale as at present (density of drivers/riders, parking availability, public transit options), and it would probably be necessary to have a way of distinguishing "registered" passengers (those with RFID devices) from those without, ${ }^{3}$ as a driver will not get credit for providing a ride to the latter.

Two different contexts for casual carpooling exist. The traditional context is where an HOV or toll lane exist, and where a carpool is granted access or reduced-fee privileges on that lane. But casual carpools could exist in any transportation corridor if there was an incentive for drivers and passengers to participate; for ease of reference these will be called non-HOV carpools.

\section{Personal Security}

The caution "not to accept a ride from a stranger" is taught at an early age. While there are characteristics of casual carpooling that tend to ameliorate that concern (random nature of pick-ups; the typical requirement for there to be at least two passengers with a driver; and in some cases the restricted corridor, as for example, crossing of the San Francisco Bay Bridge), it clearly is a concern with a significant number of people in line choosing to decline an offered ride (Burris and Wynn 2006) or reporting that the accountability of the third person was a "major factor contributing to their sense of safety" (Gidal 2004). That there are websites that exist to report on wayward behavior of drivers and/or passengers is indicative of the concern. While the success of casual carpooling demonstrates that its participants have by and large adjusted to the security issue, the unanswered question is how many people presently do not participate but might choose this commuting model if security could be enhanced?

When a driver invites a rider to enter her vehicle with a transponder and the rider has an individual RFID device, both driver and rider can be comforted by know- 
ing that the other person's identity is on file and that the ridesharing activity will be recorded as the vehicle passes reading stations. In addition, the administrative system could be designed so as to allow a commuter to provide anonymous feedback. For example, suppose a passenger is picked up by someone who drives dangerously. The system could be set up so that later in the day the passenger could access the Internet, identify himself, and indicate that on that morning's commute the driver was not recommended because of their driving. Anonymity would be preserved as the passenger would not learn who the driver was. Similarly the driver could record passenger evaluations, again anonymously. ${ }^{4}$ If the system administrator established behavioral standards, participants with a pattern of inappropriate behavior reports could be warned or excluded from participation.

\section{Reporting of Carpool Events}

Self-reporting of carpooling events when required to obtain incentives is problematic. Underreporting happens due to laziness or forgetfulness, while overreporting can be a deliberate attempt to gain undeserved rewards. With the proposed technology, this reporting would be fully automated, with the only task required being the waving of an RFID device by the transponder when entering the carpool vehicle.

\section{How Many Passengers?}

The codified "rules of conduct" associated with casual carpooling serves to put boundaries on what drivers and passengers do when sharing rides (e.g., limited conversation and no cell phones). One of the constraints on drivers is not to pick up more than the minimum number of passengers needed to qualify for use of an HOV lane (with some exceptions such as late in the commute period when drivers are infrequent). From the viewpoint of the participants, this is a perfectly sound policy: it increases the liquidity of the system by "rewarding" more drivers with passengers. But the flip side is that it encourages low-volume ridesharing and hence more vehicles on the road.

In an HOV environment, it would be better to maintain liquidity with a dynamic definition of a qualifying carpool. Suppose there was at the carpool collection point a message board that defined the number of passengers needed to qualify for HOV access as of this point in time. During peak periods this number could be set high (4+) so as to provide an incentive for maximizing vehicle load. This 
would also serve to bring into equilibrium drivers and passengers, as a driver who regularly has difficulty finding a complement of passengers will have a diminishing incentive to leave home alone in hopes of being able to form a carpool. In nonpeak periods the number of passengers required to qualify might be reduced so as both to maintain system liquidity and to provide an incentive for drivers and passengers to shift to nonpeak-hour commuting.

In non-HOV carpools, both drivers and passengers can be incentivized to maximize vehicle occupancy, either by increasing the rewards to drivers for more passengers or, more likely, adjusting the program parameters so that rewards are available only for vehicles with a higher minimum number of passengers. Rewards could also be adjusted to favor nonpeak-hour commuting. There are endless permutations of reward structures with which to experiment. One of the more intriguing observations was made in an Atlanta program (Clean Air Campaign 2004) that showed a very substantial persistence (64\%) of alternative transportation use as long as nine months to a year after the subsidies were eliminated. This suggests a program design that provided financial incentives initially might not need to be forever wedded to maintaining them (see also Beroldo 1987).

\section{Haphazard Ride Matching}

In any casual carpooling arrangement, the ability to match rider destinations with driver destinations will be imperfect. In some situations this may not matter much (e.g., in San Francisco with crossing the Bay Bridge), but in others (Washington D.C. with its multiple collection points and often multiple destinations from each point) it may. In some meeting places riders self-segregate by destination, while in others the procedure is for the driver to call out his destination and then to have the first riders in line for whom that destination works step forward. When the queue is fairly small, this could be an aggravation for a driver who is unable to complete his carpool. Signage held by riders as to destination can also be useful. Some proposals and experiments use cellular phone technology to improve this "on-the-fly" matching function (Nelson/Nygaard Consulting Associates 2006), but there are not yet any successful implementations.

While building a database of actual commuting behavior has powerful implications for creation of traditional "match lists" and prearranged carpools, it can also be used with casual carpooling. For example, a transponder reader and a message board could be located at the pick-up site. When a vehicle pulls up, the transpon- 
der could be read and the destination displayed on the message board thereby facilitating decision making by those waiting. Similarly, if the passengers passed their RFID devices by a reader as they came into the pick-up area, there could be a message board for drivers indicating destinations and number of people waiting for that destination. Having this information available could be useful to both drivers and passengers (with no passengers there would be no reason to stop, and with too many heading to the same destination a passenger might anticipate an unacceptable waiting period).

\section{Enforceability of HOV Lane Restrictions}

There is quite a literature on enforceability of HOV restrictions and considerable diversity among communities and states in terms of the rigor with which the multioccupant requirement is enforced. That there have been efforts to recover Federal funding for HOV lanes where enforcement is poor (National Transportation Library 1993) attests to the problem. Ultimately it comes down to a law official peering into the window of a vehicle and trying to count occupants, a fairly difficult task to perform in the best of circumstances, and made problematic by reclining passengers, small children, dirty or tinted windows, or inclement weather.

Devices to read vehicle transponders can be positioned anywhere along a transit corridor and can be made part of the portable equipment of an enforcement official. When a vehicle passes a reading station, it is interrogated, and if the passenger count is inappropriate, a warning message or a signal to an enforcement official could follow. Vehicles without transponders (or with the transponder turned off) would be treated as violators. The system provides for a technical validation of occupancy rather than depending on sporadic visual observation. ${ }^{5}$

\section{Diffusion of Rewards}

HOV lanes are established to encourage behavioral change that would increase the number of occupants in a vehicle. ${ }^{6}$ To the extent that the lane becomes available to users who meet the occupancy requirement but for whom there has been no decision to trade off convenience for sharing a ride, the system gets degraded (Lehman et al. 1994). For example, a family on vacation has probably not decided to include an extra family member just to qualify for HOV access but may nonetheless enjoy this access. A mother driving her children to school has probably not made a carpooling decision, while another mother who drives her neighbor's chil- 
dren along with her own may well have. The inability of the system to distinguish among participants who should have access to the reward from those who should not results in bizarre results such as the family breadwinner who commutes to work accompanied by spouse (to qualify for HOV access), where after drop-off the spouse then returns home in the vehicle only to repeat the process at the end of the day. In this case the availability of the HOV lane has doubled the vehicle usage on the highway, resulting in two round-trips rather than one.

Minimizing "free riders" (vehicles that meet occupancy requirements and gain access to an HOV lane without any behavioral change to increase occupancy levels) should follow from the eligibility requirements established during registration. For example, a program might only register commuters who have an identified place of employment, thereby eliminating most of the fortuitous eligibility (examples cited above). Although some people will benefit without having changed their behavior (e.g., a neighborhood carpool that shifts to utilize a new HOV lane), and some people might benefit even when there is a questionable net societal gain (e.g., the bus rider who chooses to casually carpool because it is faster), a careful definition of eligibility should limit this.

\section{First and Last Miles}

One of the least tractable problems with casual carpooling is the "first mile" and "last mile"-the connections from home to the casual carpooling collection point and the connections from the drop-off point to work (with the directionality reversed on the way home). One approach to addressing this could be to adopt the transit center (or "hub-and-spokes") approach used in many municipal bus lines, wherein a passenger boards a bus and goes to the transit center and then shifts to another bus to complete the trip. While this would not fit all urban areas, in places where it was feasible the logistics are not difficult. Drivers and passengers would be identified both in the approach to the hub as well as when exiting, and any monetary reward programs could reflect what was happening. Drivers could be rewarded both for bringing passengers to the hub and for transporting a probably different group to their general area of employment. Message boards at the hub could be updated in real time to show how many vehicles were approaching (along with estimates as to time of arrival) that were bound for any particular destination.

In a non-HOV environment, the possibilities for fine-tuning the operation of an enhanced casual carpooling program are endless. If, for example, persons resid- 
ing in an area consistently failed to find rides, the formula for rewarding drivers could be adjusted so as to increase the incentive for picking up passengers in that area, and this could be done until a state of approximate equilibrium between passengers and drivers was reached. Conceptually, this could be viewed as a mini municipal bus system without fixed schedules and operating without exchange of money between riders and drivers, but operating with enough frequency that concerns about not getting a ride are minimal.

\section{Extending the Reach of Casual Carpooling}

As noted earlier, casual carpooling is, at present, closely tied to the incentive of HOV lane access, although there may be some ancillary incentives such as elimination of tolls. But the basic incentive from the driver's viewpoint is reduced transit time, and for passengers it is some mixture of reduced transit time and the savings associated with not having to drive. When access to an HOV lane is not available as an incentive, if an alternative incentive (such as cash or awards) were provided, it would free casual carpooling from its dependence on HOV lanes thereby greatly extending the environments in which casual carpooling could be effective.

Numerous employer-based programs reward carpoolers with economic benefits (free parking, monthly cash payments, and merchandise awards), and these programs do not depend on the existence of HOV lanes to make them work. Because they depend on self-reporting of carpool activities, the rewards are usually modest or temporary, and they usually work only within a company and not across a community.

Estimates of what it would cost to induce someone to commute using alternative transportation (other than an SOV) can be made using historic trip reduction tables (Victoria Transport Policy Institute 2005) projected to the current year as well as reports from actual employer-based programs (Clean Air Campaign 2004; National Transportation Library 1993; Victoria Transport Policy Institute 2006). The tables distinguish environments that differ by degree of transit infrastructure present as well as costs for parking, but the financial incentive needed to cause significant shifts from SOVs to alternative modalities is not large. Given the persistence of carpooling behavior once started, a program might start with relatively large incentives that are reduced over time. Endless opportunities exist for experimentation by a program manager, and data as to the relationship between amount of incentive and participation would accumulate over time. 


\section{Funding}

With the ability to monitor actual carpooling events, employers can incentivize their employees to carpool as an alternative to using an SOV, and the program need not be limited (as is typically the case now) to programs where all the participants are employed by the same company.

Further, the ability of the system to record carpooling events could help in motivating Congress to extend the Commuter Benefit Program to add carpools to the list of modalities (currently public transit or vanpools) that are eligible for tax benefits. That they have not been included has reflected the difficulty of verifying carpooling events, but in the proposed environment, the historical record is captured and available for audit.

But the largest source of funds should come from the Regional Transportation Boards and state and federal agencies that have as their mandate the construction and operation of transportation systems. The old paradigm of simply building more roads to accommodate ever-increasing traffic should no longer be the only game in town.

To illustrate the point, in the Regional Transportation Plan for Santa Barbara County (Parsons Brinckerhoff 2006), the estimates for construction of adding an HOV lane in both directions of a 12.8-mile section of Highway 101 (currently two lanes in each direction) came to $\$ 518$ million (2006 dollars), and this did not include the cost of additional infrastructure at freeway exits and entrances. After completion of some operational improvements (now scheduled to begin in 2008), the plan estimates that 600 vehicles per peak hour would need to be eliminated to improve traffic flow to a " $D$ " level of service (the minimum level of service acceptable in the Santa Barbara Congestion Management Program.)

If the number of riders (including the driver) to qualify for a financial incentive was set at 4+, this reduction could be achieved by moving 600 SOV drivers into qualifying carpools during each of two peak hours. If drivers were incentivized by a payment of $\$ 10 /$ day (to provide a carpool to Santa Barbara in the morning and then back home in the evening), and riders were incentivized by a payment of $\$ 4$ / day, the total cost for each peak hour would be 200 (drivers) $X \$ 10+600$ (former SOV drivers) $X \$ 4=\$ 4,400$. As the program would operate for two peak-hour periods per day and approximately 250 workdays/year, the annual cost would be $\$ 4400 \times 2 \times 250=\$ 2.2$ million. If operational costs were $\$ .5$ million/year, the total 
amount would be $\$ 2.7$ million. This is well under the $\$ 3.2$ million estimated annual maintenance cost of the proposed HOV lane.

The empirical justification for the incentive numbers used in this example is that (1) they are well in excess of what the trip reduction tables (Victoria Transport Policy Institute 2005) projected to 2007 from their base year suggest would be required to cause the needed percentage of drivers to shift from an SOV to alternative transportation, and (2) they also exceed the incentives actually used in a variety of carpooling programs (Transportation Demand Institute 1997; Victoria Transport Policy Institute 2007).

The comparison to HOV maintenance costs is imperfect (since the HOV lanes would provide benefits at nonpeak commuting hours, including the weekends when summer vacation traffic can cause congestion comparable to that of the workday week), and a more complete analysis would include projections for future years. ${ }^{7}$ However, the difference in capital $\operatorname{costs}^{8}$ is so large that it should cause planners to rethink their historical commitment to capacity building.

\section{Summary}

Over the years a number of proposals have addressed the automation of ridesharing (Niles and Tolliver 1992; Dickerson 2004). While from a systems architecture point of view the vision of dynamic carpool formation is fascinating, the complexity attending these proposals has made their adoption, even as pilot programs, problematic. In contrast, the technology proposed herein is simple to implement and easy for commuters to use. It holds the promise of extending the proven concept of casual carpooling to a larger regional audience. For regions with HOV lanes, performance can be enhanced, while for regions without HOV lanes, more traditional incentive-based programs become possible.

\section{Endnotes}

1 The computation of net reduction in vehicles due to carpooling is complicated by the fact that there can be mode displacements, for example persons choosing to carpool who might otherwise use a mass transit alternative (Beroldo 1990).

${ }^{2}$ Whether the driver also obtains a personal RFID might depend on whether the vehicle could have different operators on different days. If this were not the case, 
then the vehicle's transponder could also serve to identify the driver, and an RFID device for the driver would not be required.

${ }^{3}$ Perhaps by signage, "This line for registered riders only."

${ }^{4}$ This could be a bit tricky with multiple anonymous passengers as any evaluation by the driver would need to be attributed to the right passenger.

${ }^{5}$ Some enforcement issues remain (e.g., a driver potentially "borrowing" individual RFID devices without having the individuals present in the vehicle), but discussion of this topic goes beyond this article.

${ }^{6}$ Occasionally other objectives exist. For example, some venues encourage purchase of hybrid vehicles by opening HOV lanes to these vehicles apart from occupancy count.

7 The rate at which incentive program costs increase when traffic increases and more drivers need to become carpoolers may exceed the rate at which HOV maintenance costs increase.

${ }^{8}$ The capital cost to implement the carpooling program should be comfortably less than 1 percent of the $\$ 518$ million to construct the HOV lane.

\section{References}

Beroldo, S. J. 1987. Duration of carpool and vanpool usage by clients of rides. Transportation Research Record 1130.

Beroldo, S. J. 1990. Casual carpooling in the San Francisco Bay Area. Transportation Quarterly 44 (January 1990).

Burris, Mark W., and Justin Winn. 2006. Slugging in Houston: Casual carpool passenger characteristics. Transportation Research Board Annual Meeting Paper \#06-0061.

Clean Air Campaign. 2004. http://www.ewire.com/display.cfm/Wire_ID/2235.

Dickerson, Stephen L. 2004. U.S. Patent No. 6,697,730.

Gidal, Jessica W. M. 2004. Driving with the stranger. LoudPaperMag 4 (1).

Lehman, Christopher K., Preston L. Schiller, and Kristin Pauly. 1994. Re-thinking HOV - high occupancy vehicle facilities and the public interest. Institute for Transportation and the Environment. Chesapeake Bay Foundation. 
National Transportation Library. 1993. A guidance manual for implementing effective employer-based travel demand management programs. DOT, p.6 ff. http:// www.itsdocs.fhwa.dot.gov/JPODOC5/REPTS_TE/8383.pdf.

Nelson|Nygaard Consulting Associates. 2006. RideNow! Evaluation draft report. Alameda County Congestion Management Agency (September).

Niles, John S., and Paul A. Toliver. 1992. IVHS technology for improving ridesharing. Proceedings of the 1992 Annual Meeting of IVHS America.

Parsons Brinckerhoff Quade and Douglas, Inc. 2006. 101 in motion final report. Santa Barbara County Association of Governments (July). www.101inmotion. com/FileLib/SB-101\%20Final\%20Report\%20FINAL.pdf.

Saranow, Jennifer. 2005. Some new reasons to use high-tech tolls. Wall St. Journal (August 15), Section D1.

Transportation Demand Institute of the Association for Commuter Transportation. 2007. See case studies p. 11-70 (August). www.epa.gov/otaq/stateresources/rellinks/docs/tdmcases.pdf.

U. S. Customs. 2006. Website describes the Secure Electronic Network for Travelers Rapid Inspection (SENTRI). http://www.cbp.gov/xp/cgov/travel/frequent_ traveler/sentry.

Victoria Transport Policy Institute. 2005. Trip reduction tables. http://www.vtpi. org/tdm/tdm41.htm.

Victoria Transport Policy Institute. 2006. Ridesharing (see case studies and examples). http://www.vtpi.org/tdm/tdm34.htm.

Victoria Transport Policy Institute. 2007. Commuter financial incentives. http:// www.vtpi.org/tdm/tdm8.htm.

\section{About the Author}

KALON L. KeLLEY (kalon@mtnimage.com) is a retired computer software entrepreneur and college teacher. A member of the Association for Commuter Transportation, Dr. Kelley has published articles on computer science, linguistics, and transportation. He has been active in recent years in exploring transportation alternatives for Santa Barbara County, California. 